\section{Private Practice}

I am one who holds that the maintenance of private practice in some form is essential not merely to the future advance of British surgery but to the integrity of the National Health Service. It is fundamental that every sick man should have a right to the treatment his disability requires, regardless of his ability to pay for it. It is equally fundamental that he should have the right, when in doubt, to consult an expert of undoubted standing and integrity selected and employed by himself. Without such a right, no State service can remain efficient or command respect. It is clearly in the interest of the State that those whose advice is sought in consultation and those who work in its service should be the same.

I will go further and express my conviction that the professors of all clinical subjects should not merely be allowed, but encouraged, to conduct private practice within the limits of their unit. I have urged this repeatedly at selection boards. I have outlined standing orders which would ensure that the whole work of the professor, including his private work, was available for the teaching of his subject. But my pleas fell on the deaf ears of the professors of theology, Arabic, and botany who made the appointment. The mere fact that they would not listen, that they would not try an experiment that is successful in every other country and observe its results, suggests that they were lacking in the scientific spirit.

I know admirable whole-time professors. I know none who would not be improved by private practice within the limits that I have suggested. Private practice would keep them human, for in it they would be dealing not with cases in a series but with human beings and their human families. It would keep them alert, for their supply of patients would depend on their success rather than on a professorial list. It would keep them humble, for their work would have to stand comparison with that of their colleagues.

The danger of the present position, as I see it, lies in the substitution of a label for reality, of an awarded position for an earned position. Formerly a surgeon was what he made himself in the eyes of his fellows. He started as one to be watched, became one to be employed, and finally one to be consulted. To-day he walks into a board-room a registrar and comes out a consultant. Formerly he climbed the ladder of professional standing carefully, under watchful and not always friendly eyes. He studied what had already been done and what results had already been obtained before he started to invent new methods, and he made very sure of the soundness of his innovations before he published them. To-day he is no sooner appointed than he designs a new operation, one that ignores past experience and physiological principles, and he blares it abroad with all the ballyhoo of an advertisement for a new detergent without waiting to observe its results. It is as wrong for a surgeon to undertake a difficult operation for which he has not been trained as it is for a man to run a sports car through a football crowd before he has passed his driving test. It is as criminal for a surgeon to practise and publish a new operation without complete study as it is for a manufacturer to put a dangerous drug on the market without previous laboratory tests.

Now that surgery has become a nationalized industry the nation must surely recognize that it is one in which skill and wisdom are acquired slowly, progressively, and by apprenticeship. The two grades at present recognized in surgery, registrar and consultant, do not recognize the progressive nature of surgical training and the gradual release of supervision and assumption of responsibility that is necessary in any surgical service. There is need for an intermediate grade, one comparable to that of a surgical specialist with the rank of major in the Army, an assistant surgeon of specialist rank, responsible for his own beds and his own out-patient sessions, but advised to some extent by consultant colleagues and remunerated on a scale intermediate between that of registrar and consultant. Such a grade would absorb many of the senior registrars who are in fact doing the work, and give them the security of tenure that they now lack.

\section{Conclusion}

To conclude, I must disagree with Erichsen. The end is not yet. A multitude of problems remain to be solved. Though much is known about peptic ulceration and its treatment, the whole answer still eludes us. The discovery of the cause of cancer seems to be as far off as ever, but the cause of sarcoma, which is surely a different disease from carcinoma, may be found in our lifetime. If the pioneers of the past had failed to inspire others to build on the foundations which they had laid, the progress of surgery would have come to an end long ago.

Let me quote from the translation of a hymn from the Sanskrit :

Listen to the Salutation of the Dawn,

Look to this Day,

In its brief course lie all the verities and realities of your existence.

For to-day well lived makes every yesterday a dream of happiness, every to-morrow a vision of hope-

Look well therefore to this day.

\section{CHEYNE-STOKES RESPIRATION AN OXIMETER STUDY}

BY

\section{H. R. GILMORE, M.B., M.R.C.P., M.R.A.C.P.} AND

\section{H. KOPELMAN, M.D., M.R.C.P.}

(From the Department of Medicine, Postgraduate Medical School of London)

Cheyne-Stokes respiration is an easily recognized condition, the features of which are said to have been described by John Hunter (Gibson, 1892). Its presence during waking hours in patients suffering from cardiac or cerebral disease is thought to point to a serious prognosis and usually an early death. The nature of the mechanism which starts and perpetuates this disorder is still obscure, and it is therefore more than a passing physiological curiosity.

Traube (1871), who advanced the first noteworthy theory of the mechanism of Cheyne-Stokes respiration, described two groups of cases-those with intracranial lesions but without heart disease, and those with cardiac disease but no intracranial lesions. Common to both these groups, he thought, was cerebral anoxaemia, which diminished the normal response of the respiratory centre. This factor, however, cannot alone be the explanation of the phenomenon, for reasons discussed by several observers (Harrison 1939 ; Resnick and Lathrop, 1925), and by simple clinical experience with patients suffering from severe anoxaemia:

Much the same inadequacy is found with theories which seek an explanation on the basis of a deranged control of carbon dioxide tension in the blood. Fishberg (1937), in whose text is to be found a full description of these theories together with the clinical manifestations of Cheyne-Stokes respiration, says that this condition seems " especially common in those cases of hyperten- 
sive and arteriosclerotic heart failure in which there are palsies and other signs of arteriosclerotic disease of the brain."

Apart from those cases in which Cheyne-Stokes respiration occurs as a complication of cerebral compression or intoxication with morphine-like drugs, there remains the great bulk of instances in which this condition is found associated with varying forms of heart disease. The disorder is not uncommon, but CheyneStokes respiration occurring in a chronic and persistent form is rare, although Sansom (1892) described the condition in the aged. This report presents a description of two patients in whom chronic Cheyne-Stokes respiration was a prominent feature, and describes investigations using an ear oximeter in patients with this form of respiration.

\section{Material and Methods}

The Ear Oximeter.-The oximeter used was a commercial model produced by the Waters Conley Company, Rochester, Minnesota, and is a modification of an instrument described by Wood and Geraci (1949). This makes use of infra-red and red filters over photoelectric cells connected to a bucked circuit so that the arterial oxygen saturation can be read directly by observing the galvanometer light on a calibrated scale. The underlying theory of this instrument is fully described by Wood (1950). The apparatus was modified by arranging in front of the galvanometer scale a dropping plate camera taken from an old Cambridge electrocardiograph. The galvanometer beam was thus photographed during the interval of time taken for the plate to fall, which was varied from approximately one to four minutes. Into this system a second-time marker was incorporated. This instrument was used for recording changes in the arterial oxygen saturation which occurred during the varying phases of respiration and the changes produced by the use of oxygen, carbon dioxide, and aminophylline. Simultaneous respiratory recordings were made, using a simple pneumogram apparatus recording on a kymograph whose speed was synchronous with that of the rate of fall of the photographic plate.

Determination of the Mean Circulation Time.-The spectral characteristics of the dye Evans blue (T. 1824) are such that changes in the concentration of this dye in blood may be detected by means of the ear oximeter. Wood and Geraci (1949) have shown that, with a suitable recording system, time-concentration curves of the dye can be obtained following the rapid intravenous injection of the dye. These correspond closely with the curves obtained from rapid arterial samples (Hamilton et al., 1932 ; Kopelman and Lee, 1951) from which the mean circulation time from the site of injection to the recording site can be calculated. In these patients 20 to $30 \mathrm{mg}$. of the dye made up in a $1 \%$ solution was used, but for repeated tests smaller quantities can be used as described by Gilmore et al. (1954). Five patients with obvious Cheyne-Stokes respiration and with cardiac lesions were investigated. In two of these CheyneStokes respiration persisted for many months, and these are described in some detail.

\section{Case 1}

This patient, a civil engineer aged 47 , was a known case of chronic rheumatic heart disease with mitral stenosis and auricular fibrillation. In June, 1951, he developed a rightsided hemiplegia and aphasia due to a cerebral embolus, from which he made a good recovery. He was admitted to Hammersmith Hospital in January, 1952, semicomatose, eleven hours after a further cerebral embolus to the opposite side of the brain.

Examination showed pseudo-bulbar palsy with inability to protrude the tongue, to talk, or to swallow. There was cardiac enlargement, with the typical signs of mitral stenosis, without evidence of congestive failure, but with slow auricular fibrillation. The blood pressure was $130 / 60$. His colour was normal and he showed no evidence of cyanosis. Marked Cheyne-Stokes respiration with apnoeic intervals of over half a minute was present. To exclude cerebral compression a lumbar puncture was done, and the pressure and fluid were found to be normal. It was thought that he had had an embolus to the right internal capsule, which, together with the previous lesion, had given rise to a pseudobulbar palsy.

He was fed by stomach tube, and two days after admission developed bronchopneumonia and became very ill and cyanosed. As the respiratory rate increased and breathing became laboured, the Cheyne-Stokes respiration disappeared. In an oxygen tent the cyanosis disappeared and his respira-

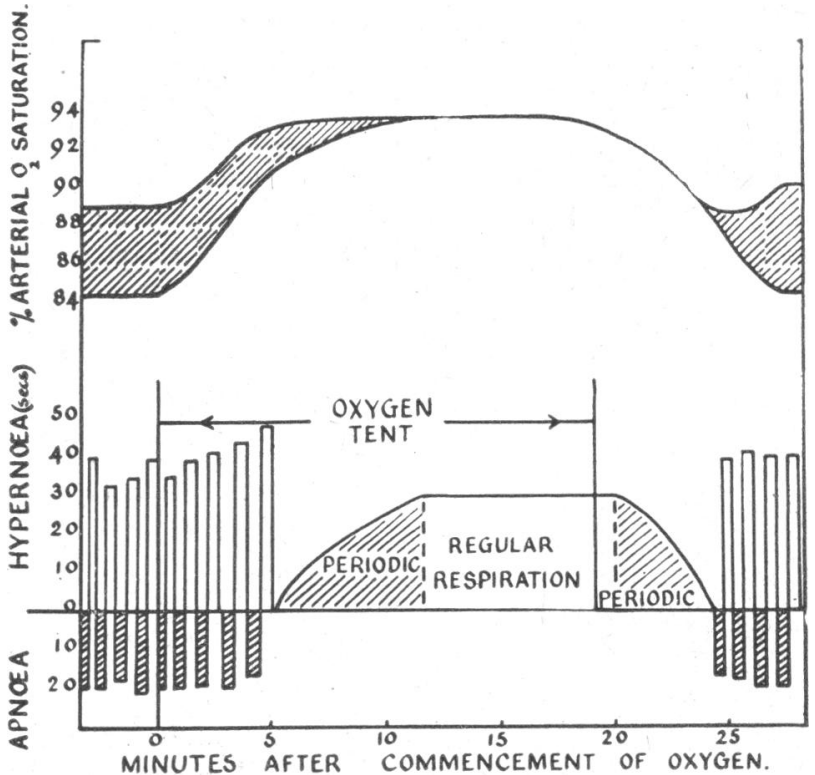

FIG. 1.-Case 1. Diagram showing effect of oxygen on the respiration and arterial oxygen saturation in a patient with Cheyne-Stokes respiration.

tory rate fell but remained regular. He slowly improved, and in a few days was able to protrude his tongue a little and to swallow liquids. On removal from the oxygen tent for nursing it was noted that the Cheyne-Stokes respiration soon recurred (see Fig. 1). It was also seen that on these occasions he lost consciousness during the periods of apnoea and woke again soon after he began the period of hyperpnoea.

Despite further general treatment Cheyne-Stokes respiration continued, but there was no loss of consciousness during the apnoeic phase, although he was unable to talk during this period.

In view of his loss of consciousness during the apnoeic phase an E.E.G. was done while he was breathing air and showing Cheyne-Stokes respiration and, subsequently, while breathing oxygen, which obliterated this form of respiration. No difference could be detected in the curves taken during the respiratory phases of Cheyne-Stokes respiration and little change was caused by breathing oxygen.

$\mathrm{He}$ was discharged in March and was able to walk with support. There was some dysarthria but no aphasia, and his heart condition was satisfactory. Despite this, CheyneStokes respiration was still a marked feature, with apnoeic phases up to twenty seconds in length. Improvement continued, but the Cheyne-Stokes respiration persisted with shorter apnoeic phases and was now easily obliterated by attracting his attention. In December he had a further embolus, and was admitted to another hospital: this illness proved to be fatal. Unforiunately, there was no necropsy. 


\section{Case 2}

This patient, aged 64, attended the out-patient department on October 31, 1951, having for three weeks complained of increasing shortness of breath on exertion. He had been blind for seven years. Apart from the increasing effort dyspnoea, he had been very well.

It was apparent that he had well-developed Cheyne-Stokes respiration with apnoeic phases prolonged beyond half a minute. Examination showed him to have free aortic-valve

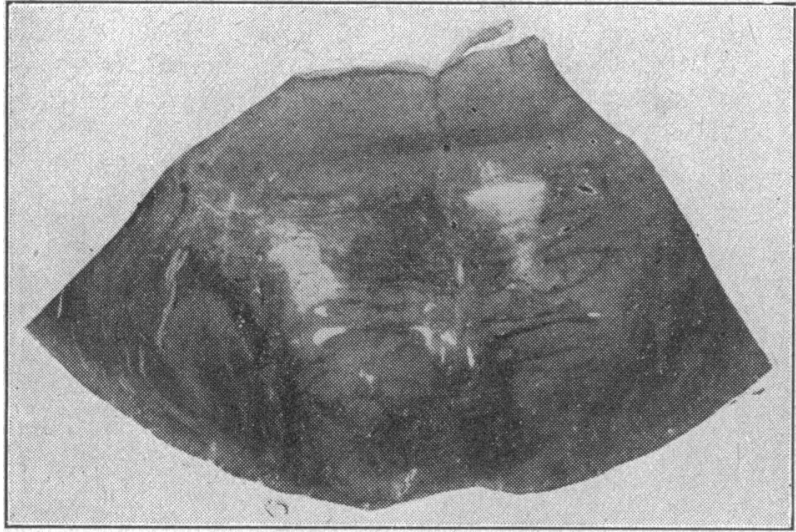

FIG. 2.-Case 2. Section of pons showing symmetrical foci of loss of substance in the reticular part. (PTAH. $\times 3$.)

incompetence with left ventricular enlargement, presystolic gallop rhythm, and a collapsing pulse. The blood pressure was $170 / 50$. Basal rales were present in his lungs and there was a little oedema of the ankles. He was thought to be suffering from left ventricular failure, and was admitted to hospital.

The Wassermann reaction and Kahn test were found to be strongly positive and the chest $x$-ray film was suggestive of aneurysmal formation of the ascending aorta. Lumbar puncture gave normal results with a pressure of $70 \mathrm{~mm}$.

All the evidence of left ventricular failure soon disappeared with rest in bed and digitalis treatment, but the Cheyne-Stokes respiration still persisted even after he was allowed to get up and walk about.

He was discharged from hospital and was able to care for himself and an invalid wife, although he was still showing Cheyne-Stokes respiration with apnoeic periods up to twenty seconds in length.

The Cheyne-Stokes respiration was noted at each outpatient attendance, but he continued in reasonable health until readmitted at the beginning of April, 1952, when the evidence of left ventricular failure again was present, though still slight. He became apathetic and difficult to keep adequately nourished, and finally developed bilateral suppurative parotitis, lapsed into coma, and died. Even terminally the evidence of left ventricular failure was minimal. Since his first attendance he had been observed for six months, with Cheyne-Stokes respiration persisting throughout.

Necropsy Findings.-These briefly were (1) left and right ventricular hypertrophy; (2) aneurysm of the ascending aorta with syphilitic scarring of the aortic cusps ; (3) wasting; and (4) bronchitis and bronchopneumonia. The brain, $1,285 \mathrm{~g}$., showed normal meninges and cerebral arteries (free of atheroma). Coronal sections revealed two small areas of softening involving the white matter anteriorly in the right frontal lobe. Sections taken through the pons at the level of the junction of the middle and inferior thirds showed two small symmetrical foci of softening and gliosis in the reticular substance on each side of the midline. The dimensions of these areas were roughly 3 by $5 \mathrm{~mm}$. in section and were not more than $2.5 \mathrm{~mm}$. in length. Section of the medulla at mid-olive level showed no lesion (Fig. 2)

\section{Results}

Arterial Oxygen Saturation

It was found that rhythmical fluctuations in arterial oxygen saturation of $4 \%$ to over $10 \%$ were recorded during the respiratory phases in individual cases (see Table). Simultan-

Fluctuations in Arterial Oxygen Saturation During the Respiratory Phases

\begin{tabular}{|c|c|c|c|c|c|}
\hline $\begin{array}{l}\text { Case } \\
\text { No. }\end{array}$ & $\begin{array}{l}\text { Length } \\
\text { of } \\
\text { Apnoea } \\
\text { (Secs.) }\end{array}$ & $\begin{array}{c}\text { Length } \\
\text { of } \\
\text { Hyperpn. } \\
\text { (Secs.) }\end{array}$ & $\begin{array}{c}\text { Lowest } \\
\mathrm{O}_{2} \\
\text { Saturation } \\
\%\end{array}$ & $\begin{array}{c}\text { Highest } \\
\mathrm{O}_{2} \\
\text { Saturation } \\
\%\end{array}$ & $\begin{array}{l}\text { Mean } \\
\text { Circn. } \\
\text { Time } \\
\text { (Secs.) }\end{array}$ \\
\hline 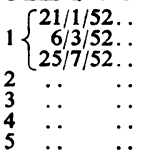 & $\begin{array}{l}30 \\
22 \\
18 \\
44 \\
20 \\
14 \\
40\end{array}$ & $\begin{array}{l}33 \\
42 \\
45 \\
59 \\
50 \\
30 \\
55\end{array}$ & $\begin{array}{l}89.0 \\
90 \cdot 5 \\
90 \cdot 0 \\
89.0 \\
91.5 \\
81.0 \\
76.5\end{array}$ & $\begin{array}{l}94.5 \\
95.0 \\
93.5 \\
94.0 \\
94.5 \\
89.5 \\
92.5\end{array}$ & $\begin{array}{l}34 \\
32 \\
26 \\
45 \\
25 \\
25 \cdot 5 \\
38\end{array}$ \\
\hline
\end{tabular}

eous pneumograms showed that the greatest degree of unsaturation occurred during hyperpnoea and not during apnoea as might be expected. Indeed, the arterial saturation was at its highest during apnoea (Fig. 3). Although Anthony et al. (1932) did not find this paradoxical result, it has been described many times before (Matthes, 1943 ; Pryor, 1951). Apart from Case 4, whose oxygen saturation fell to $81 \%$, the overall depression in arterial oxygen saturation was slight.

When normal subjects varied their respiration to mimic that of the Cheyne-Stokes type the response of the arterial oxygen saturation as recorded by the ear oximeter was as follows. The arterial oxygen saturation began to rise about nine seconds after breathing was started, the highest satura-

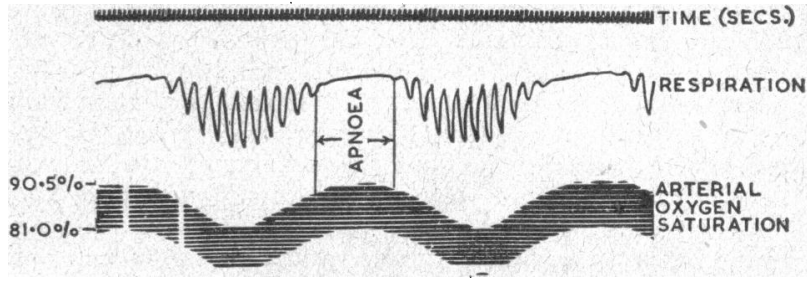

FIG. 3.-Case 4. The oxygen saturation is highest approximately in the middle of the apnoeic phase and lowest during the hyperpnoeic period. The oxygen saturation is read from the top of the photographed galvanometer beam, which also shows calibration divisions.

tion occurring at the end of the respiratory phase. After the onset of apnoea the saturation soon began to fall, and was lowest just after the end of the apnoea.

In the patients with true Cheyne-Stokes respiration the mean circulation times obtained after the intravenous injection of Evans blue dye are all prolonged beyond the normal range. These circulation times were obtained using the oximeter as described by Gilmore et al. (1954).

\section{Effects of Oxygen Administration}

The changes produced by oxygen were studied in Case 1 during his recovery from bronchopneumonia, while he was still being treated in an oxygen tent. In the oxygen tent his respirations were regular and arterial saturation was $95 \%$. When he was taken out of the tent his arterial oxygen saturation fell steadily to $88 \%$, his respirations becoming at first periodic-that is, showed regular phasic fluctuations without apnoea and then typically CheyneStokes in type with a long period of apnoea. It was noted that during the apnoeic phase, when his arterial saturation was $91 \%$, he became unconscious, waking again almost immediately he began the hyperpnoeic phase, when his saturation was down to $86 \%$. After returning to the oxygen tent his respiration quickly became periodic, with arterial oxygen saturation varying between 91.5 and $94.5 \%$. This was soon replaced by regular normal respiration, with the saturation steady at $95 \%$ (Fig. 1). 


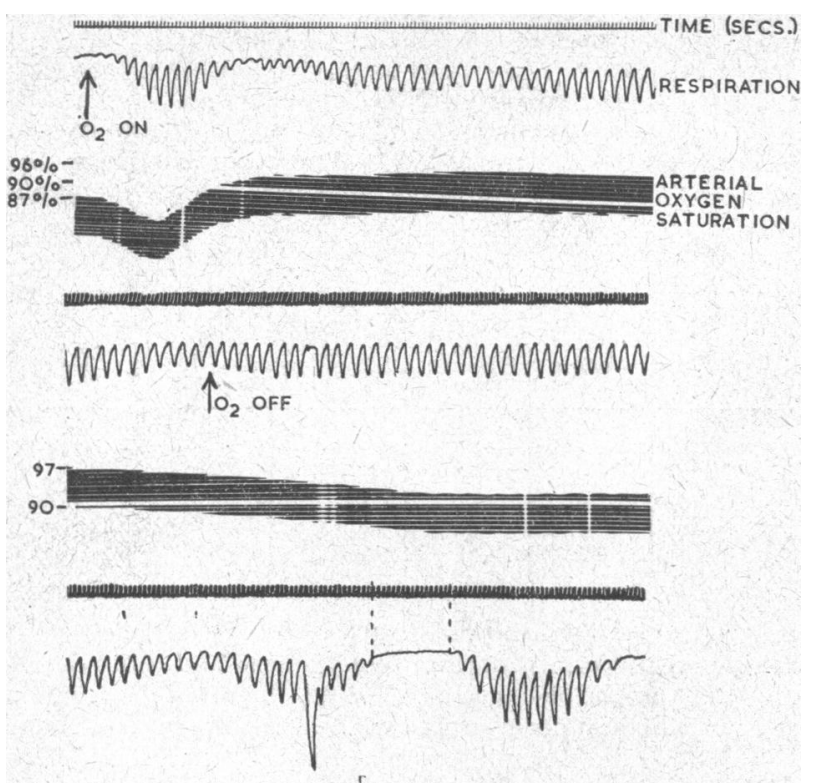

ing air, the respirations rapidly became shallower, with a gradual but small falling off in arterial oxygen saturation. Periodic respiration returned in less than a minute after removing the carbon dioxide inhalation.

It is to be noted that regular deep respiration began within fifteen seconds of the administration of $7 \%$ carbon dioxide, although the maximum steady arterial oxygen saturation was not reached until a further forty-five seconds had elapsed, and that this was no greater than was seen during the apnoeic phase.

\section{Effects of Aminophylline}

When aminophylline was given slowly by intravenous injection Cheyne-Stokes respiration soon yielded to regular normal respiration. This occurred initially without any rise in arterial oxygen saturation, although subsequently there was some increase due to the improved ventilation from the regular respiration (Fig. 6). It was found that the effects of $0.25 \mathrm{~g}$. of aminophylline given intravenously lasted an hour or so. Circulation times which were done before and after administration of the drug - that is, during Cheyne-Stokes and regular respiration-showed no significant difference.
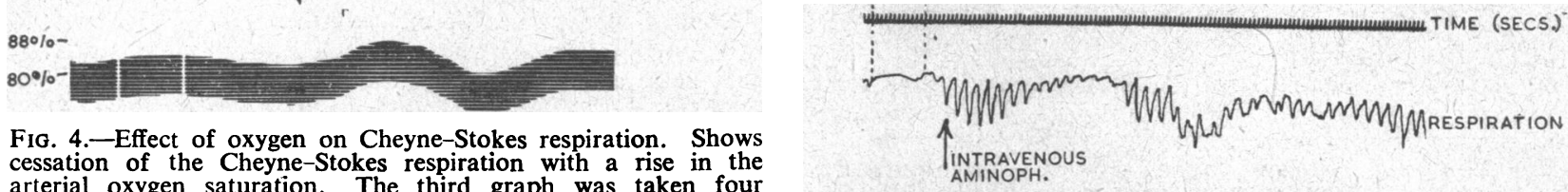

Fig. 4.-Effect of oxygen on Cheyne-Stokes respiration. Shows cessation of the Cheyne-Stokes respiration with a rise in the arterial oxygen saturation. The third graph was taken four minutes after the oxygen mask was removed.

The effect of oxygen given by B.L.B. mask at 8 litres a minute was subsequently studied in all five patients. In all of them it was found that the oxygen saturation rose steadily to 95 or $96 \%$, and that at this level the CheyneStokes respiration was replaced by normal regular respiration. After the removal of oxygen, regular respiration continued for some minutes, but was accompanied by a slow, steady fall in arterial oxygen saturation. When, in each individual case, a constant critical level in saturation was reached, the respiration became at first periodic and subsequently typically Cheyne-Stokes (Fig. 4).

\section{Effect of Carbon Dioxide}

The inhalation of $7 \%$ carbon dioxide caused a rapid replacement of Cheyne-Stokes by regular deep respiration. In Case 1, whose results are shown in Fig. 5, the arterial oxygen saturation, which had been fluctuating between 90 and $94 \%$, rose gradually over one minute to $93.5 \%$ and then remained steady. On switching the patient to breath-
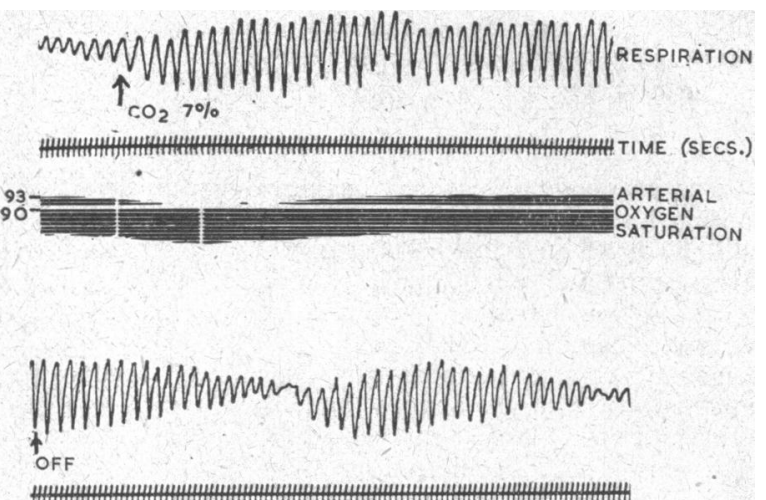

$93 \%$

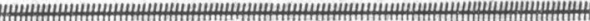

$90 \%$

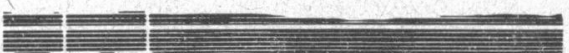

FIG. 5.-Effect of carbon dioxide on Cheyne-Stokes respiration. Deep regular respirations occur with but slight change in arterial oxygen saturation and the effect of the carbon dioxide ceases very soon after removal of the mask.

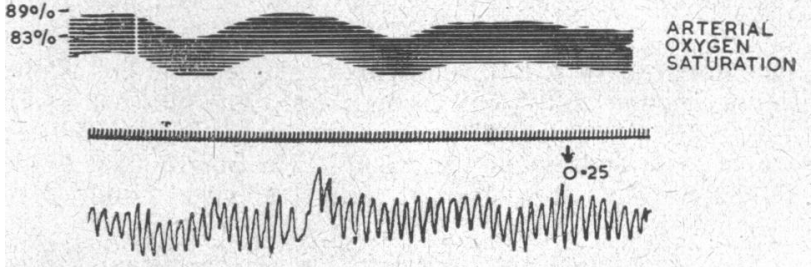

$90 \%-$

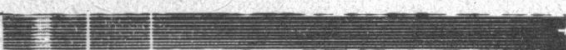

Fig. 6.-Effect of intravenous aminophylline. Regular respiration occurred soon after the injection began, with little change in arterial saturation. This persisted for sixty minutes after the injection of $0.25 \mathrm{~g}$. was completed.

\section{Other Clinical Manifestations}

Changes in blood pressure and pulse rate seen during the phases of Cheyne-Stokes respiration are diagrammatically shown in Fig. 7. The blood pressure appeared to be highest in the last quarter of the respiratory phase and lowest during the second half of apnoea. The pulse rate showed a varied response, but in one patient (Case 4), with a sinus bradycardia of 54, there was no change in rate, though during each apnoeic phase two or three ventricular premature beats occurred. Pupil changes were noted only in Case 1 and were as shown in Fig. 7.

The changing state of consciousness in Case 1 was of special interest. In the days immediately following the cerebral embolism the loss of consciousness during the apnoeic periods was profound and he was unresponsive to visual or auditory stimuli. With abolition of the CheyneStokes respiration by oxygen, carbon dioxide, or aminophylline, he remained continuously alert and responsive. With his general improvement, although the Cheyne-Stokes respiration persisted, the unconsciousness of the apnoeic phase disappeared, but he was unable to continue a conversation during the period of apnoea. Subsequently he was able to continue talking during the apnoeic period, but it required an obvious effort of will.

In cases with prolonged periods of apnoea, external stimulation or voluntary effort on the part of the patient did not affect the periodicity or the duration of the apnoeic period. In the less severe cases the attachment of recording 
apparatus or external stimuli of many types can obliterate the Cheyne-Stokes respiration. This change was well seen in Case 1 as he progressed and gradually improved.

The carbon dioxide content of arterial blood in the two phases of the cycle was estimated in one patient. Although the carbon dioxide tension in the arterial blood was not directly measured, the carbon dioxide content was lowest during the apnoeic phase, and it may be assumed that during this phase the carbon dioxide tension reached its lowest level.

\section{Discussion}

The delay in the circulation time constantly found in these patients accounts for the paradoxical findings in the arterial oxygen saturation during the phases of the CheyneStokes cycle. Thus the fully oxygenated blood returning from the lungs in the hyperpnoeic phase is delayed in appearing in the systemic circulation, as shown by the prolongation in the arm (or lung) to ear (or brain) circulation time. From the results (see Table) there is a suggestion that a relationship exists between the duration of the apnoeic phase and the extent of prolongation of the circulation time. It is obvious, however, that this cannot alone account for the Cheyne-Stokes respiration, as many cases of congestive cardiac failure with greater prolongation of circulation time and more arterial unsaturation do not snow this form of respiration. There must therefore be an additional factor or factors in these patients who demonstrate Cheyne-Stokes respiration.

Coincidental with the brisk rise in arterial oxygen saturation when patients breathe oxygen, there is a rapid obliteration of Cheyne-Stokes respiration. Following the removal of the oxygen, the arterial oxygen saturation shows a slow fall over some minutes, and when this reaches some critical level of unsaturation there is a return to the Cheyne-Stokes respiration. The falling oxygen saturation in the arterial blood has been suggested as the stimulus which ends the apnoeic phase. This is unlikely, because although the arterial oxygen saturation is past its peak it is still high when respiration recommences, and, again, the administration of oxygen should cause a period of apnoea rather than convert the Cheyne-Stokes to normal respiration. The work of Selladurai and Wright (1932), Nielsen (1936), and Åström (1952) suggested that oxygen lack diminishes the sensitivity of the respiratory centre to changes in the carbon dioxide of the blood. However, more recently Nielsen and Smith (1952) have shown that in hypoxia the respiratory centre is actually more sensitive to slight changes in carbon dioxide tension than it is under normal conditions. It would appear that oxygen obliterates Cheyne-Stokes respiration by changing the sensitivity of the respiratory centre to the prevailing carbon dioxide tension of the blood, but that this effect is secondary to some primary change in the respiratory centre itself.

The respiratory centre consists of inspiratory and expiratory components which are situated in the medulla, and a pneumotaxic centre in the pons which rhythmically inhibits the other parts (Gray, 1950) and which itself receives stimuli from the higher centres of the brain. In one patient (Case 1), diagnosed as having pseudo-bulbar palsy, the embolic lesions probably involved the coriico-bulbar pathways, which is the site usually affected. Extensive search of the brain in Case 2 showed that the main lesions were in the middle pons (Fig. 2), which are above the probable anatomical position of the medullary respiratory centres. Thus in both these patients there existed lesions probably above the respiratory centre itself, but interrupting the pathways connecting the higher centres to this lower vegetative centre. It is suggested that the response of the respiratory centre is so altered by disruption of its neural connexion that a relatively slight degree of anoxaemia changes its sensitivity. In these circumstances a greater degree of carbon dioxide tension is required for its stimulation, thereby providing one factor in the formation of the cyclic respiratory rhythm.

Thus it seems that the fortuitous combination of these cerebral lesions on the one hand, and the prolonged circula- 
during apnoea, so that anoxaemia cannot by itself be held responsible. The carbon dioxide tension is, however, at its lowest during the apnoeic phase (Harrison, 1939), and, since cerebral blood flow is directly related to the carbon dioxide tension of the blood (Kety and Schmidt, 1946), reduction of blood flow from this cause may be responsible. We have no data on this aspect.

\section{Summary}

Two patients with chronic Cheyne-Stokes respiration are described in some detail. These with a further three patients were investigated, using an ear oximeter.

It has been shown that the highest arterial oxygen saturation occurs during the period of apnoea, the lowest during the hyperpnoeic interval. This is due to a delay in circulation time and has been demonstrated by means of dye time-concentration curves. The length of the apnoeic phase seems to be related to the prolongation of the circulation time.

The effects of oxygen, carbon dioxide, and aminophylline on this condition have been studied together with their effect on arterial saturation.

In our patient with chronic Cheyne-Stokes respiration a mid-brain lesion is described. The mechanism causing this form of respiration is discussed.

It is suggested that two of the factors are a prolongation of circulation time and a change in sensitivity of the respiratory centre. The latter may arise from interruption of cortical pathways to this centre.

We should like to express our thanks to Dr. Jean Taylor for the pathological reports, to Dr. Gerald Parsons-Smith for the E.E.G. report, and to Dr. Ian Milne, of Montreal, for his assistance.

\section{REFERENCES}

Anthony, A. J., Cohn, A. E., and Steele, J. M. (1932). J. clin. Invest., 11, 1321 .

Aström, A. (1952). Acta physiol. scand., Suppl. 98

Fishberg, A. M. (1937). Heart Failure. Lea and Febiger, Philadelphis.

Gibson, G. A. (1892). Cheyne-Stokes Respiration. Oliver and Boyd Edinburgh.

Gilmore, H. R., Hamilton, M., Kopelman, H., and Sommer, L. S. (1954) Brit. Heart J., 16, 301

Gray, J. S. (1950). Pulmonary Ventilation and its Physiological Regulation. Thomas, Springfield.

Hamilton, W. F., Moore, J. W., Kinsman, J. M., and Spurling, R. G (1932). Amer. J. Physiol., 99, 534.

Harrison, T. R. (1939). Failure of the Circulation, 2nd ed. Bailliere Tindall and Cox, London.

Kety, S. S., and Schmidt, C. F. (1946). J. clin. Invest., 25, 107.

Kopelman, H., and Lee, G. de J. (1951). Clin. Scl., 10, 383.

Matthes, K. (1943), Z. ges. exp. Med., 112, 486

Moyer, J. H., Miller, S. I., Tashnek, A. B., and Bowman, R. (1952). J. clin. Invest., 31, 267.

Nielsen, M. (1936). Skand. Arch. Physiol., 74, Suppl. No. 10, 83.

- and Smith, H. (1952). Acta physiol. scand., 24, 293.

Pryor, W. W. (1951). Circulation, 4, 233.

Pesnick, W. H and Lathrop. F. W (1925). Arch intern. Med 36, 229. (1892). The Diagnosis of Diseases of the Heart and Thoracic Aorta. Griffin, London.

Selladurai, S. and Wright, S. (1932) Ouart. J. exp. Physiol. 22, 233.

Traube, L. (1871). Gesammelte Beiträge zur Pathologie und Physiologie, 2. 882 Hirschwald, Berlin.

Wechsler, R. L., Kleiss, L. M., and Kety, S. S. (1950). J. clin. Invest., (29, 28 .

Wood, E. H. (1950). In Medical Physics, edited by O. Glasser, 2, 664 Year Book Publishers Chicago.

and Geraci, J. E. (1949). J. Lab. clin. Med., 34, 387.

Official Records of the World Health Organization No. 55 is a paper-backed volume of 512 pages recording the resolutions and decisions taken at the Seventh World Health Assembly, which was held in Geneva from May 4 to 21, 1954. In addition, the volume contains verbatim records of the eleven plenary sessions, minutes and reports of ten committees, and eight annexes. The price is $£ 1$, and there are both French and English editions. The series of Official Records includes each year the annual report of the directorgeneral, the programme and budget estimates, proceedings of the World Health Assembly, reports of the executive board, and the financial report and report of the external auditor. In addition to these annual reports, other volumes are published as required.

\section{THE NATURE OF GASTRIC HYPER- SECRETION OF ACID IN PATIENTS WITH DUODENAL ULCER}

\author{
BY
}

J. N. HUNT, D.Sc, M.B., B.S.

Department of Physiology, Guy's Hospital, London

AND

A. W. KAY, M.D., Ch.M., F.R.C.S.Ed.

Peptic Ulcer Clinic, Western Infirmary, Glasgow

Gastric contents of high acidity are more often encountered in patients with duodenal ulcer than they are in normal persons (Enticknap and Merivale, 1954 ; James and Pickering, 1949). The high concentration of acid of the gastric contents in such patients is at least in part the result of an increased secretion of acid. As it is probable that a highly acid gastric content retards the healing of a duodenal ulcer, the abnormality causing the hypersecretion is a matter of clinical interest.

Gastric secretion is reflex. It depends upon the stimulation of receptors which, acting either by nervous or by hormonal channels, excite the secretory cells. The ultimate factor limiting the response of gastric secretory arcs is the maximal secretory capacity of the mucosa. If this can be measured it becomes possible to describe the gastric response to any stimulus as a percentage of the maximal secretory capacity. Viewed in this light, hypersecretion may be divided into two classes. In one, the maximal secretory capacity is normal, but the proportion of that capacity which is at work is raised. Here we may assume that there is an increase in stimulation bearing on the parietal cells. In the other, the maximal secretory capacity is abnormally high-perhaps owing to an abnormally large number of parietal cellsso, although the proportion of that capacity which is actively engaged in secretion is normal the resulting output is excessive. In this type we may conclude that the stimulus is quantitatively normal. This paper is concerned with deciding into which class the hypersecretion of patients with duodenal ulcer falls. It will be shown that patients with duodenal ulcer have an abnormally high maximal secretory capacity.

It will also be shown that the development of stenosis in duodenal ulcer patients is associated with a raised maximal secretory capacity.

A Maximal Stimulus for the Parietal Cells.-Histamine stimulates the acid-secreting cells of the stomach directly, since it is effective in isolated mucosa. It is possible to evoke from the stomach an apparent maximal output of acid by giving large doses of histamine while protecting the patient against the extragastric actions of histamine by previous administration of an antihistaminic (Kay, 1953). In the present paper this maximum is used as an index of the maximal secretory capacity of the gastric mucosa.

\section{Methods}

Material.-The augmented histamine test has been made on 27 males without a history of dyspepsia and on 152 male patients in whom duodenal ulcer was proved by subsequent operation. The basal and maximal secretions were examined and the results have provided the material for statistical analysis. 